\title{
Depressive symptoms in older adults in basic health care
}

Gesualdo Gonçalves de Abrantes' (ID)

Geovana Gomes Souza' ${ }^{1}$ Nilza Maria Cunha²

Hélder Novais Barreto da Rocha ${ }^{3}$ (D)

Antonia Oliveira Silva ${ }^{4} \mathbb{D}$

Selene Cordeiro Vasconcelos ${ }^{2}$ (D)

\section{Abstract}

Objective: To identify depressive symptoms in older adults treated in primary care. Method: A descriptive-exploratory cross-sectional quantitative study was conducted with 260 older adults registered with Family Health Units in João Pessoa, Paraíba, Brazil. A sociodemographic instrument and the Geriatric Abridged Depression Scale (GDS-15) were applied. Descriptive analysis summarized the variables through percentages and number of participants. Results: There was a prevalence of older adults aged 60-70 years $(\mathrm{n}=154 ; 59.2 \%)$, who were female $(\mathrm{n}=186 ; 71.5 \%)$ and had a low educational level $(\mathrm{n}=89$; $34.2 \%)$. The GDS-15 revealed that $195(75.0 \%)$ of the older adults had no depressive symptoms. It was observed that $219(84.2 \%)$ older adults were satisfied with their lives, $198(76.1 \%)$ felt happy most of the time, 194 (74.6\%) were in a good mood most of the time, $236(90.8 \%)$ reported feeling hope in their lives and $248(95.4 \%)$ mentioned feeling that it was wonderful to be alive. In addition, 135 (51.9\%) older adults preferred to go out rather than stay at home, $180(69.2 \%)$ felt full of energy, and $226(86.9 \%)$ considered themselves useful people, although 112 older adults (43.0\%) had interrupted many of their activities and $141(54.2 \%)$ feared that something bad would happen. Conclusion: Primary Health Care is responsible for the screening of depressive symptoms in older adults to implement actions to protect and promote the health of this population. It is a guiding strategy of the care process, aimed at stimulating active aging and autonomy, as well as the prevention of health problems. This study contributes to reflections on the importance of public policies and good practices in the care of older adults.

\footnotetext{
Universidade Federal da Paraíba, Departamento de Enfermagem. João Pessoa, PB, Brasil.

2 Universidade Federal da Paraíba, Departamento de Enfermagem em Saúde Coletiva. João Pessoa, PB, Brasil.

3 Faculdade Instituto de Desenvolvimento Educacional, Movimente Wellness. Recife, PE, Brasil.

4 Universidade Federal da Paraíba, Instituto Paraibano de Envelhecimento. João Pessoa, PB, Brasil.
}

Research Funding: Scientific Research Mentorship Program - Universidade Federal da Paraíba - Coordination for the Improvement of Higher Education Personnel (UFPB-CAPES). Edital 2017 PIBIC/PIVIC - UFPB/CNPq. The authors declare there are no conflicts of interest involved in this study

Keywords: Geriatric Psychiatry. Public Health. Primary Health Care. Mental Health. Depression. 


\section{INTRODUCTION}

Depression is highly significant contemporary social problem, and an issue that must be discussed and reflected upon from different conceptual perspectives in order to obtain a broader knowledge and understanding that can guide decision making in clinical practice.

Depression is conceptualized by the World Health Organization ${ }^{1}$ as a common mental disorder characterized by sadness, loss of motivation, lack of pleasure and oscillations between feelings of guilt and low self-esteem. In addition to sleep or appetite disorders, it causes social and psychological harm, affecting autonomy, freedom and lifestyle, and is related to the aggravation of chronic diseases and impairments to the physical and mental performance and social life of the individual ${ }^{2}$. Behavioral changes may be the first sign of a possible diagnosis of affective disorders ${ }^{3}$.

The aging process is a set of several interrelated physiological, morphological, biochemical and emotional changes, which are progressive and gradual and marked by motor and sensory losses, and which make individuals more vulnerable and susceptible to diseases, causing damage to their functionality ${ }^{4}$. Decline in physical health is considered the main risk factor for depression, and is related to disability and greater dependence ${ }^{5}$.

Depression is one of the most prevalent chronic diseases in old age, and is related to increased morbidity and mortality, deficits in self-care and low adherence to treatments. It becomes a public health problem due to its individual, family and social repercussions, which include, in addition to financial costs, the use of health services and the decrease in quality of life ${ }^{6}$. However, older adults can perceive themselves as healthy and socially active when they can fulfill their expectations and plans through daily activities, building positive attitudes and images about old age ${ }^{7}$.

Based on the above, it appears that aging is a natural process of the life cycle, which is both complex and multifaceted. At the same time it is considered to be a period of loss, and a moment of discovery, opportunity and change towards an active and healthy aging. However, respect and care should be encouraged, according to the demands and needs of older adults. The present study therefore aimed to identify depressive symptoms in older adults being treated in primary care.

\section{METHOD}

An observational, descriptive-exploratory, crosssectional study with a quantitative approach was carried out, following the guidelines proposed by the Strengthening the Reporting of Observational Studies in Epidemiology (STROBE) document. It was implemented in Family Health Units (FHU) attached to Health District II in the city of João Pessoa, Paraíba, Brazil, from August to December 2017.

Sample size calculation was performed using the $\mathrm{R}$ software package, with a $5 \%$ margin of error, a 95\% reliability that the margin was not exceeded and an expected prevalence of $50 \%$, in order to obtain a value that maximized the sample size, based on a registered population in these units of 394 older adults. The final sample comprised 260 such adults.

The inclusion criteria were: older adults registered in the health units surveyed, regardless of gender. The exclusion criteria were any physical or mental conditions that made it difficult to understand the research instruments, a situation subjectively assessed by the research team throughout the interview.

The sample was selected at random and for convenience, with the selection of the older adults based on the medical records of the families registered in the health units, and subsequent recruitment through prior contact with the community health agents who organized the home visits for the carrying out of the research.

Data collection was preceded by the training of the research team through study meetings and discussions on the theme and instruments, as well as the simulation of the application of instruments among the participants. However, supervision by the advisor professor was required during the first two data collections. 
A sociodemographic questionnaire, developed by the research team, was used to characterize the profile of the participants, as well as the Abbreviated Geriatric Depression Scale (GDS15). These instruments were applied among the participants by three research students, with an approximate duration of 40 minutes. A friendly and conducive space for reception and conversation and was provided, and the sessions were carried out when all the patients were receiving treatment. Most of the older adults were accompanied by a family member or caregiver during the survey, and these individuals were told that they could not interfere with the interview.

The Abbreviated Geriatric Depression Scale (GDS-15), validated in Brazil, was used in the study. This tool investigates the presence of depressive symptoms and the worsening of symptoms in older adults, and consists of 15 questions with binary answers (yes or no). The scores produced range from 0 to 5 , classifying the older adults as "no depressive symptoms", and 6 points and above, meaning "some depressive symptoms", with 5 considered the cutoff point ${ }^{8}$.

The sociodemographic data were tabulated and analyzed using the Statistical Package for Social Science (SPSS), version 21.0, using descriptive statistics tools.
The study complied with the ethical principles of Resolution no 466/2012 of the National Health Council ${ }^{9}$, and was approved by the Ethics Committee for Research Involving Human Beings under opinion $n^{\circ} 2.190 .153$.

\section{RESULTS}

Most of the older adults were aged between 60 and 70 years old $(n=154 ; 59.2 \%)$, female $(n=186$; $71.5 \%)$ and had low education levels $(\mathrm{n}=89 ; 34.2 \%)$ (Table 1).

The results from the analysis based on the Geriatric Depression Scale (GDS-15) showed that 195 (75.0\%) older adults were classified as having "no depressive symptoms" (Table 2). However, 25 (9.6\%) older adults with 5 points in the GDS- 15 were identified, a score considered to be the cut-off point for this scale. This is of clinical significance as these individuals can be considered to be borderline between the absence and presence of depressive symptoms.

The analysis of the GDS-15 variables shows that $219(84.2 \%)$ older adults said they were satisfied with their life, 193 (74.2\%) did not find their life empty, $170(65.4 \%)$ did not frequently get bored and $194(74.6 \%)$ were in good spirits most of the time. However, 141 (54.2\%) older people feared that something bad would happen to them (Table 3).

Table 1. Sociodemographic characteristics of the older adults (N=260). João Pessoa, Paraíba, 2017.

\begin{tabular}{ll}
\hline Variables & $\mathrm{n}(\%)$ \\
\hline Sex & \\
Male & $74(28.5)$ \\
Female & $186(71.5)$ \\
\hline Age (years) & \\
60 to 70 & $154(59.2)$ \\
71 to 80 & $75(28.8)$ \\
81 to 90 & $26(10.0)$ \\
91 or more & $5(2.0)$ \\
Schooling (years of study) & \\
No schooling & $21(8.1)$ \\
1 to 5 & $89(34.2)$ \\
6 to 10 & $59(22.7)$ \\
$\geq 11$ & $67(25.8)$ \\
Did not respond & $24(9.2)$ \\
\hline
\end{tabular}


Table 2. Depressive symptoms identified based on the Abbreviated Geriatric Depression Scale (GDS-15) (N=260). João Pessoa, Paraíba, 2017.

\begin{tabular}{ll}
\hline GDS-15 Points & $\mathrm{n}(\%)$ \\
\hline 0 to 5: no depressive symptoms & $195(75.0)$ \\
$\geq 6$ or more: depressive symptoms & $65(25.0)$ \\
Total & $260(100.0)$ \\
\hline
\end{tabular}

Table 3. Distribution of responses of older adults to the Abbreviated Geriatric Depression Scale (GDS-15) (N=260). João Pessoa, Paraiba, 2017.

\begin{tabular}{lll}
\hline Variable & Yes & No \\
$\mathrm{n}(\%)$ & $219(84.2)$ & $41(15.8)$ \\
\hline 1.Are you satisfied with your life? & $112(43.1)$ & $148(56.9)$ \\
2.Have you dropped many of your activities? & $67(25.8)$ & $193(74.2)$ \\
3.Do you feel that your life is empty? & $90(34.6)$ & $170(65.4)$ \\
4.Do you often get bored? & $194(74.6)$ & $66(25.4)$ \\
5.Are you in good spirits most of the time? & $141(54.2)$ & $119(45.8)$ \\
6.Are you afraid that something bad is going to happen to you? & $198(76.1)$ & $62(23.8)$ \\
7.Do you feel happy most of the time? & $39(15.0)$ & $221(85.0)$ \\
8.Do you often feel helpless? & $125(48.1)$ & $135(51.9)$ \\
9.Do you prefer to stay at home, rather than going out? & $52(20.0)$ & $208(80.0)$ \\
10.Do you feel you have more problems with memory than most people? & $248(95.4)$ & $12(4.6)$ \\
11.Do you feel it is wonderful to be alive? & $34(13.1)$ & $226(86.9)$ \\
12.Do you feel worthless? & $180(69.2)$ & $80(30.8)$ \\
13.Do you feel full of energy? & $24(9.2)$ & $236(90.8)$ \\
14.Do you feel that your situation is hopeless? & $67(25.8)$ & $193(74.2)$ \\
15. Do you think that most people are better off than you are? & &
\end{tabular}

It was observed that 198 (76.1\%) older adults were happy most of the time, 39 (15.0\%) felt helpless and $248(95.4 \%)$ said they thought it was wonderful to be alive. In addition, 135 (51.9\%) older adults preferred to stay at home, $180(69.2 \%)$ felt energetic and 226 $(86.9 \%)$ considered themselves useful, but 112 (43.0) $\%$ ) such adults had dropped many of their activities.

\section{DISCUSSION}

The sociodemographic characteristics identified in this study corroborate the findings of another study $^{10}$. The results showed a higher prevalence of older women, a phenomenon known as the feminization of old age, which occurs due to the longer life expectancy of women, related to lower exposure to risk and greater health care and services in Basic Health Units (BHU) ${ }^{11}$.

Studies indicate that low levels of education are related to the occurrence of depressive symptoms in older adults, promoting reflections on the relationship between schooling and the ability to cope with depressive symptoms ${ }^{12,13}$, guiding care actions aimed at the empowerment of these adults and co-responsibility for their health care.

Similarly, a study showed a difference in depressive symptoms depending on sex, with a higher prevalence of depressive symptoms in women ${ }^{14}$. Understanding the gender-related peculiarities of older adults may support specific care actions for this population. 
The present study showed that the older adults were both satisfied with their lives and happy, illustrating that happiness is an important indicator of well-being, which may be a protective factor against depressive symptoms. However, a study conducted in Portugal with 119 older adults, $65.5 \%$ of whom were women and $34.5 \%$ of whom were men, with an average age of 78 years, identified another reality, composed of older people who were dissatisfied with their lives and described themselves as sad and anxious, aspects that were related to harm to their interpersonal, family and social relationships, quality of life and impairments of physical, mental and functional capacity ${ }^{3}$.

Feeling energetic can contribute to the acquisition of healthy habits, such as regular exercise, which promotes beneficial effects such as stress relief, due to the increased production of endorphins that act on nerve connections to control the internal environment and responses to the environment, increasing the ability to cope with environmental stress $^{15}$. In addition, it is considered an aspect of active and healthy aging and part of the pursuit of improvements in overall health and protection against cognitive impairment ${ }^{16}$.

Almost all of the older adults in the study said that they felt it was wonderful to be alive, and that they felt useful and hopeful; attributes that enable activities that promote socialization and interpersonal relationships are important for quality of life and better mental health ${ }^{17}$. Such thoughts are essential individual tools for coping with depressive symptoms during any life cycle, especially during the aging process.

Some older adults in this study reported concern with memory problems, which represents another important aspect to be investigated by the primary care team, guiding actions to prevent depressive symptoms and promote mental health care ${ }^{18}$.

In this sense, investigations into the context in which older adults are inserted, their lifestyles and health-promoting behaviors are indispensable for the promotion of comprehensive care for this population. These aspects are considered attributes for physical and mental well-being, contributing to life satisfaction and engagement in activities aimed at a better quality of life, and which can delay or prevent the onset of depressive symptoms ${ }^{19}$.

The limitations of the present study include the research design, as a cross-sectional study reveals only a specific aspect of the reality investigated, as well as the difficulty in recruiting and accessing the older adults in their homes.

Based on the above, the main contributions of this study to geriatrics and gerontology are that it promotes reflections on the screening and monitoring of depressive symptoms in older adults, demonstrating that primary health care is an important scenario of care. Knowledge of the life context of older adults promotes a deeper understanding of aspects that permeate their lives, as well as their perception of factors related to depressive symptoms. Teaching and research also represent care strategies, based on the production of scientific evidence that can guide actions that promote and protect the health of older adults and their families, as well as specific referrals based on the findings.

\section{CONCLUSION}

The study identified the occurrence of depressive symptoms in older adults registered in family health units. The abbreviated geriatric depression scale showed that the older adults were satisfied with their own lives and that this satisfaction is related to healthy living, the practice of varied activities, leisure and an active memory. In addition, the older adults were found to be happy, participative, active and happy, who felt useful and among whom high spirits contributed to a feeling of hope.

An active life affects the quality of life and social life of an individual and contributes to the improvement of mental capacity. The present study identified the importance of implementing public policies and practices that promote well-being and healthy aging, as well as the screening and monitoring of depressive symptoms in older adults.

Edited by: Ana Carolina Lima Cavaletti 


\section{REFERENCES}

1. Organização Mundial de Saúde. Relatório Mundial de Envelhecimento e Saúde. Genebra: OMS; 2015.

2. Siu AL, Bibbins-Domingo K, Grossman DC, Baumann LC, Davidson KW, Ebell M, et al. Screening for depression in adults: US Preventive Services Task Force recommendation statement. JAMA. 2016;315(4):380-7.

3. Martins RM. A depressão no idoso. Spectrum. 2016;(34):119-23.

4. Menezes JNR, Costa MDPM, Iwata ACDNS, de Araujo PM, Oliveira LG, de Souza CGD, et al. A visão do idoso sobre o seu processo de envelhecimento. Rev Contexto Saúde. 2018;18(35):8-12.

5. Prata HL, Alves Junior EDD, Paula FL, Ferreira SM. Envelhecimento, depressão e quedas: um estudo com os participantes do Projeto Prev-Quedas. Fisioter Mov. 2017;24(3):437-43.

6. Luppa M, Sikorski C, Luck T, Ehreke L, Konnopka A, Wiese B, et al. Age-and gender-specific prevalence of depression in latest-life: Systematic review and meta-analysis. J Affect Disord. 2012;136(3):212-21.

7. Veloso LDSG, Veloso JAP, Miguel MDGD, Gouveia MLA, Colella TLA, Moreira MASP. Cognitive Capacity and Depressive Symptoms in Elderly People Attending the Primary Care Services. Rev Pesqui Cuid Fundam. 2018;10(4):1182-7.

8. Almeida OP, Almeida SA. Short versions of the geriatric depression scale: a study of their validity for the diagnosis of a major depressive episode according to ICD-10 and DSM-IV. Int J Geriatr Psychiatry. 1999;14(10):858-65.

9. Brasil. Conselho Nacional de Saúde. Resolução n0 466, de 12 de dezembro de 2012. Aprova Diretrizes e normas regulamentadoras de pesquisas envolvendo seres humanos. Diário Oficial da União. 13 jun. 2013; Seção 1: p. 59.

10. Silva PAB, Santos FC, Soares SM, Silva LB. Sociodemographic and clinical profile of elderly persons accompanied by Family Health teams under the gender perspective. Rev Pesqui Cuid Fundam Online. 2018;10(1):97-105.
11. Camargos MCS, Gonzaga MR. Viver mais e melhor?: estimativas de expectativa de vida saudável para a população brasileira. Cad Saúde Pública. 2015;31(7):1460-72.

12. Brodaty H, Altendorf A, Withall A, Sachdev P. Do people become more apathetic as they grow older?: a longitudinal study in healthy individuals. Int Psychogeriatr. 2010;22:426-36.

13. Groeneweg-Koolhoven I, de Waal MW, Van Der Weele GM, Gussekloo J, Van Der Mast RC. Quality of life in community-dwelling older persons with apathy. Am J Geriatr Psychiatry. 2014;22:186-94.

14. Mendes-Chiloff CL, Lima MCP, Torres AR, Santos JLF, Duarte YO, Lebrão ML, et al. Sintomas depressivos em idosos do município de São Paulo, Brasil: prevalência e fatores associados (Estudo SABE). Rev Bras Epidemiol. 2019;21:e180014 [16 p.].

15. Sanchez MA, Brasil JMM, Ferreira IAM. Benefícios de um programa de atividade física para a melhoria da qualidade de vida de idosos no estado do Rio de Janeiro. Rev Bras Ciênc Envelhec Hum. 2014;11(3):209-18.

16. da Silva JF, do Nascimento Júnior JRA, de Araújo APS, de Oliveira DV. Análise comparativa da qualidade de vida de idosas praticantes de exercícios físicos em centros esportivos e nas academias da terceira idade. Rev Bras Ciênc Envelhec Hum. 2016;13(3):285-98.

17. Ferreira L, Roncada C, Tiggemann CL, Dias CP. Avaliação dos níveis de depressão em idosos praticantes de diferentes exercícios físicos. Conscientiae Saúde. 2014;13(3):405-10.

18. Raymundo TM, Boligon B, Canales EB, Nascimento MXC, Bernardo LD. Treino cognitivo para idosos: uma estratégia interventiva utilizada pela Terapia Ocupacional. Rev Ocupación Hum. 2017;17(2):5-19.

19. Marques JFS, de Sá SC, de Freitas Filho W, do Espírito Santo LR, de Prince KA, de Oliveira MVM. Transtorno depressivo maior em idosos não institucionalizados atendidos em um centro de referência. Arq Ciênc Saúde. 2017;24(4):20-4. 